\title{
Electronic Lab Report Management System Based on Network Technology
}

\author{
Huichun Huang \\ Southeast University \\ Nanjing, China \\ huanghuichun@seu.edu.cn
}

\author{
Renjie $\mathrm{Hu}$ \\ Southeast University \\ Nanjing, China \\ hurenjie@seu.edu.cn
}

\author{
Guoliang Du \\ Southeast University \\ Nanjing, China \\ dugl@seu.edu.cn
}

\begin{abstract}
Relying on advanced educational technology, integrated teaching environment and modern management, electronic lab report management system has been developed with computer network technology. It could assist the personalized student-centered open experiment teaching and full process management of students`experiments. So it meets the requirements of the information age.
\end{abstract}

Keyword-Electronic Lab Report; Experimental Process Management; Computer Network Technology

\section{INTRODUCTION}

Theoretical teaching and experimental teaching and scientific research are the three basic elements of higher education personnel training. The teaching of experiment is an important part of teaching system in electronic engineering. It is very important for mastery of the course content, the enhancement of practice and ability of innovation. The teaching of experiment is complex system engineering. The good subjective desire, the advanced ideas and reasonable mode of teaching must be relying on the advanced educational technology, integrated teaching environment and modern management tools to be implemented [1]. The lab report is an important part of the experiment. Conventional paper-based lab report has been unable to meet the requirements of the information age. There are lots of problems with it, such as difficulties in data and waveform input, teacher-student interaction and comprehensive analysis. In order to achieve comprehensive management of experimental teaching, Electrical and Electronic Experiment Center of Southeast University has been trying to grope in recent years, after nearly two years of research, construction, implementation and perfection, the experiment center has designed the electronic lab report management system with advanced educational philosophy as a guide and computer network as technology. The system consists of hardware and software systems. The system has played a good role in carrying out the personalized student-centered open experiment teaching model.

\section{HARDWARE COMPONENTS OF ELECTRONIC LAB REPORT MANAGEMENT SYSTEM}

The electronic lab report management system requires certain hardware to support it, such as the terminal equipment including instruments, data acquisition unit and computer, the management facilities including allocation terminal, power control adapter, power controller, PDA for experiment teaching and servers including Web server, streaming media server and laboratory management server [2]. These hardware facilities are preconditions of the experiment process management. The system hardware components are shown in Figure 1.
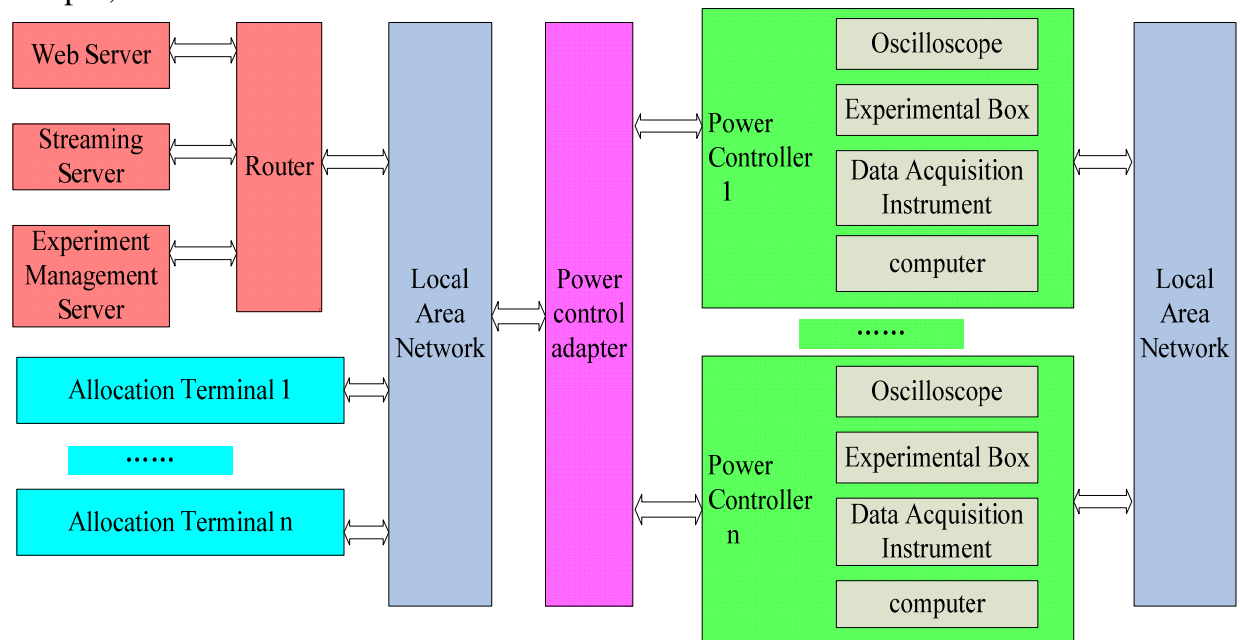

Figure 1. System Hardware Components

As shown in Figure 1, the allocation terminal was placed on laboratory building foyer, the number of which is 
3-4 units. The allocation terminal automatically assign experimental seat for students when he brush campus card. Student was authorized to enter the appropriate laboratory of the access control system. And the power control adapter switch the power of corresponding lab desk on. During the experiment, the data acquisition unit acquires critical data and waveform, and uploads them to the database in servers. This provides the conditions for the electronic lab report management system.

Among the whole set of hardware facilities, data acquisition [3] unit is an important device for the electronics lab report. It is a virtual instrument set of digital oscilloscope, logic analyzer and arbitrary waveform generator, which connecting PC via USB. Students make the test interface like probe of oscilloscope or logic analyzer be connected with corresponding signal. Then use electronic lab report software on the computer to display the data and waveform. After confirmation, the collected experiment data and waveform are directly imported to the electronic lab report. Due to the use of automatic allocation system, a digital signature of the student can be embedded in all the data and waveform. This eliminates the need for manual records, and also prevents plagiarism, falsification of experiment data.

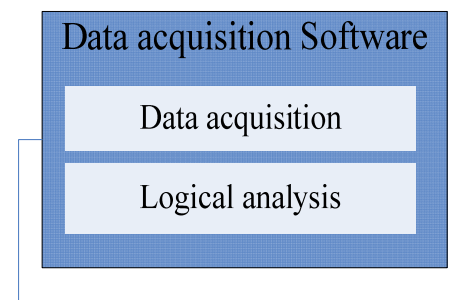

4

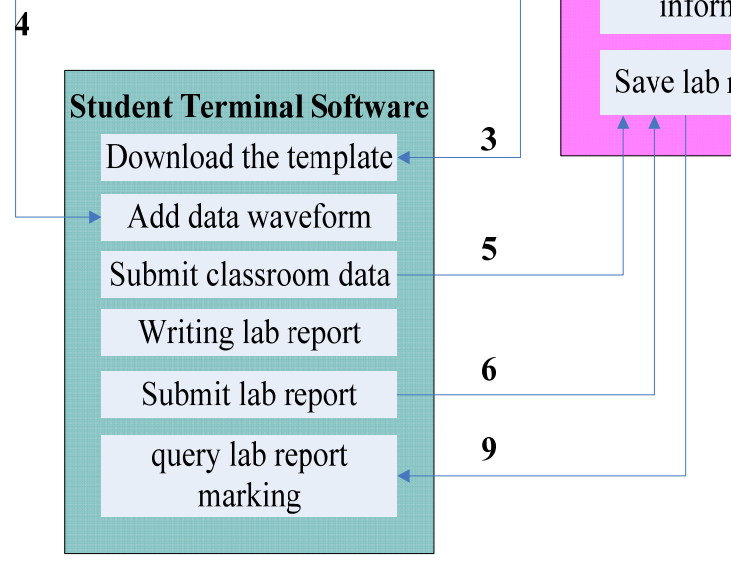

Figure 2. Software Function Modules

\section{A. The management of design before experiment}

Teachers made the report template according to teaching plans and content. In the template, the preview requirements, the experiment content and data acquisition module were set. After the template being uploaded to the server, students could download and complete them according to the requirements. They could simulate design and apply for the BOM. The instructor could check the

\section{SOFTWARE FUNCTION OF ELECTRONIC LAB REPORT MANAGEMENT SYSTEM}

Laboratory information management system [4] contains teaching resources management, teaching system management, experimental course management, experimental process management, student assessment management, extracurricular practice management, teacher appraisal management, equipment management, system maintenance and management.

The software of electronic lab report management system is a subsystem of the laboratory information management system. It manages the process of students experiment. In accordance with the principle of the convenient data entry, efficient and instant exchange of teachers and students, the system has been designed with three major functional modules, which covering the whole process of experiment from previewing, recoding to summarizing. The three modules manage the follows: the design before the experiment, the data acquisition during the experiment and submitting, correcting and statistics after the experiment. Each function modules are designed with the clients for student and teachers. This allows students and teachers to real-time interaction through the network. Figure 2 shows the software function modules [5]. 
time, the instructor could check the uploaded data and waveform and guide students in real time. This realized the whole process guidance during the experimental.

\section{The management of submitting, correcting and statistics after the experiment}

After the experiment, the students analyzed the experimental data and summarized the results. They uploaded the report to the server using client software. Teachers using the teachers' client could correct the report online or offline. After that, students could instantly view their report. The efficiency of teaching and learning has been improved.

Teacher client software can import / export lab report for archive, and access the submitting and correcting information of the reports for the feedback of the completion status of students in each experiment. It can also generate a variety of statistical reports for improving the teaching quality as a good reference.

\section{CONCLUSION}

Electronic lab report management system based on network technology has been put in trial running since 2007 results, which solved the contradiction between the personalized experiment guidance and open experiment teaching management and improved the teaching quality and management efficiency. The one hand, it urged students to preview before the experiment, measure data and waveform during the experiment, analyze and summarize the result after experiment. The other hand, it facilitated the interaction between students and teachers during the experiment and improved the interactive effect of the teaching process. Electronic lab report management system is applicable to the electric and electronic engineering courses. Various types of statistics can be generated by teachers according to needs to meet the requirements of the information age.

\section{REFERENCES}

[1] Luo Hanyang, “An online collaborative learning mode in management information system experimental teaching,"Source: Lecture Notes in Electrical Engineering, v 72 LNEE, p 351-357, 2010, Advances in Wireless Networks and Information Systems.

[2] CHANG Chun, "Research and practice of net working comprehensive experiment teaching management system," Experimental Technology and Management, Vo.l 24 No. 6,June 2007, chinese.

[3] WANG Zheng, "Oscilloscope Design Based on Virtual Instrument Platform,” No.4, 2009,pp34-36,chinese.

[4] HU Renjie, "Constructing Teaching-Experiment Management System and Carrying outScientific NormalManagement,” Research and Exploration in Laboratory, Vol.31 No.4,May 2007,pp9-11,chinese.

[5] HUANG Huichun, "Management System of Electronic Experimental Report Based on Electronic Information and Computer Network Technology," Research and Exploration in Laboratory, Vol.31 No.4,April 2012,pp259-261,chinese. 